\title{
Proliferative Effects of Bovine and Porcine Thyroglobulins on Thyroid Epithelial Cells
}

\author{
Moyuru HAYASHI*, Motoyuki SHIMONAKA*, Kozo MATSUI*, TAKAYUKi HAYASHI*, Daisuke OCHIAI*, \\ AND NAOYA EMOTO** \\ * Department of Chemistry, Tokyo University of Science, 1-3 Kagurazaka, Shinjuku-ku, Tokyo 162-8601, Japan \\ **Department of Endocrinology, Nippon Medical School Chiba-Hokusoh Hospital, 1715 Kamagari, Inba-mura, Chiba 270-1694, Japan
}

\begin{abstract}
Thyroglobulin is the precursor of the thyroid hormones, triiodothyronine and thyroxine. Because the molecular size of thyroglobulin is relatively large $(660 \mathrm{kDa})$, it could have other additional functions besides serving as the precursor of the thyroid hormones. In this report, we examined the proliferative effects of thyroglobulins purified from bovine and porcine thyroid tissues on the growth of a rat thyroid follicular cell line, FRTL-5, as well as the primary culture of porcine thyroid epithelial cells. Bovine and porcine thyroglobulins stimulated the proliferation of not only FRTL-5 cells but also porcine thyroid epithelial cells in a dose-dependent manner. The proliferative effect of thyroglobulin was neutralized by an anti-thyroglobulin monoclonal antibody but not by two different anti-fibroblast growth factor antibodies. The stimulatory signal of thyroglobulin was transmitted via the phosphatidylinositol 3-kinase pathway. Also, removal of the N-linked oligosaccharides on thyroglobulin reduced the proliferative activity of porcine thyroglobulin, suggesting that the proliferative effect of thyroglobulin is in part exerted by its carbohydrate moiety. Taken together, we have demonstrated for the first time that thyroglobulin possesses proliferative effect on thyroid epithelial cells in addition to being the precursor of the thyroid hormones.
\end{abstract}

Key words: thyroglobulin, thyroid epithelial cells, FRTL-5 cells, carbohydrate chain

(Endocrine Journal 56: 509-519, 2009)

THYROGLOBULIN (Tg) is a relatively large glycoprotein with a molecular mass of $660 \mathrm{kDa}$ and is composed of two identical subunits. It is the precursor of the thyroid hormones, triiodothyronine $\left(\mathrm{T}_{3}\right)$ and thyroxine $\left(\mathrm{T}_{4}\right)$. At the preferential sites of tyrosine residues within a $\mathrm{Tg}$ molecule, iodide is incorporated to form iodotyrosine residues and then $\mathrm{T}_{3}$ and $\mathrm{T}_{4}$ residues are generated by the coupling of these iodotyrosine residues. In addition to the iodinated tyrosine residues, $\mathrm{Tg}$ contains several domains, such as the 11 type- 1 cysteine-rich repeats, an acetylcholinesterase homologous domain, a receptor binding domain, a thioredoxin box, as well as the antigenic epitopes [1]. Tg is synthesized in the thyroid epithelial cells, which form fol-

Received: November 26, 2008

Accepted: February 19, 2009

Correspondence to: Motoyuki SHIMONAKA, Ph.D., Department of Chemistry, Tokyo University of Science, 1-3, Kagurazaka, Shinjuku-ku, Tokyo 162-8601, Japan licles, and the mature $\mathrm{Tg}$ is released into and stored in the lumen of these follicles. Tg is the most abundant protein in the thyroid gland and the concentration of $\mathrm{Tg}$ in the follicles averages between $100 \mathrm{mg} / \mathrm{ml}$ to 400 $\mathrm{mg} / \mathrm{ml}[2,3]$. The most important function of $\mathrm{Tg}$ is to provide a scaffold for the synthesis of the thyroid hormones and also to serve as a reservoir for iodide and the thyroid hormones, ready for their release.

Besides serving the classical function as a precursor for the thyroid hormones, $\mathrm{Tg}$ has been shown to act as a transcriptional regulator on thyroid-specific genes, including thyroid peroxidase, thyrotropin receptor, sodium iodide symporter, and the transcription factors TTF-1, TTF-2, and Pax-8 as well as Tg itself $[4,5]$. Through the regulation of the transcription of these factors it has been speculated that $\mathrm{Tg}$ regulated the follicular content of iodide [6]. In addition, it has been reported that $\mathrm{Tg}$ also had transforming growth factor- $\beta$-like activity when it is activated by chemical modification, treatment with denaturing agents, or 
acidification [7]. Furthermore, it was recently reported that $\mathrm{Tg}$ stimulated the proliferation of mouse mesangial cells, which suggested the involvement of $\mathrm{Tg}$ in cell signaling in non-thyroidal tissues [8]. However, no investigation has been conducted to evaluate whether $\mathrm{Tg}$ regulates the proliferation of thyroid cells.

Many studies have reported on the regulation of thyroid cell proliferation by TSH [9], insulin/insulinlike growth factor I (IGF-I) [10, 11], and other growth factors, including fibroblast growth factor-2 (FGF-2) [12] and epidermal growth factor [13]. These studies were conducted by using various cell culture systems, such as primary cultures of rat, dog, sheep and human thyroid cells as well as using rat thyroid cell lines, such as FRTL-5, WRT, and PC Cl3. The signaling pathways on cell proliferation have also been extensively investigated but some discrepancies still exist, depending on which experimental model systems were being used [reviewed in 9]. In the present study, we have examined whether Tg from bovine or porcine thyroid gland affect the proliferation of the primary culture of thyroid epithelial cells as well as a rat FRTL-5 thyroid follicular cell line. Our results showed that Tgs from bovine and porcine species stimulated the proliferation of both porcine thyroid epithelial cells and FRTL-5 cells.

\section{Materials and Methods}

\section{Materials}

Bovine Tg was purchased from Sigma, USA, anti-human Tg monoclonal antibody was from HyTest Ltd, Finland, anti-IGF-I monoclonal antibody was from Thermo Fisher Scientific, USA, and anti-FGF-1 and anti-FGF-2 monoclonal antibodies were from Wako Pure Chemical, Japan. Chromatography media, DEAE-Sepharose, Sephacryl S-300, Sepharose 4B were from GE Healthcare Bioscience, USA, and Ham's F12 Nutrient Mixture Medium, antibioticantimycotic solution, and bovine serum were from Invitrogen, USA. N-glycosidase $\mathrm{F}$ was from Roche Diagnostics, Germany, and wortmannin, transferrin, Gly-His-Lys acetate, hydrocortisone, somatostatin, insulin, and TSH were from Sigma. Dispase was purchased from Sanko Junyaku, Japan. Cell counting kit and 5-bromo-2'-deoxy-uridine (BrdU) labeling and detection kit were purchased from Wako Pure
Chemical and Roche Diagnostics, respectively.

\section{Purification of porcine thyroglobulin from thyroid tissues}

Porcine thyroid glands were purchased from a local slaughterhouse. Purification of Tg was performed according to a published method [14] with slight modification. Briefly, the thyroid tissues $(20-30 \mathrm{~g})$ were homogenized in 10-tissue volumes of phosphate-buffered saline (PBS: $15 \mathrm{mM}$ phosphate, $140 \mathrm{mM} \mathrm{NaCl}, \mathrm{pH} 7.0$ ) containing proteinase inhibitors $(250 \mu \mathrm{M}$ PMSF, $5 \mu \mathrm{g} /$ $\mathrm{ml}$ pepstatin, $5 \mu \mathrm{g} / \mathrm{ml}$ leupeptin, $500 \mu \mathrm{M}$ benzamidine, $250 \mu \mathrm{M}$ EDTA). The homogenate was centrifuged at $100,000 \mathrm{x} \mathrm{g}$ for $60 \mathrm{~min}$ and the $\mathrm{Tg}$ in the supernatant was precipitated with ammonium sulfate at between $35 \%$ to $45 \%$ saturation. The precipitated Tg was dissolved in $20 \mathrm{mM}$ phosphate buffer, $\mathrm{pH} 6.5$, dialyzed against the same buffer and then applied to a DEAESepharose column. The adsorbed proteins were eluted with a linear gradient of $\mathrm{NaCl}(0-1.0 \mathrm{M})$ in $20 \mathrm{mM}$ phosphate buffer, $\mathrm{pH}$ 6.5. The fractions containing $\mathrm{Tg}$ identified by immunoblotting were combined and applied to a Sepharose 4B gel filtration column equilibrated in $2.0 \mathrm{M} \mathrm{NaCl}$ in $20 \mathrm{mM}$ phosphate, $\mathrm{pH} 6.5$, to remove any other proteins that could bind to the $\mathrm{Tg}$ carbohydrates by electrostatic interaction. To resolve the isolated $\mathrm{Tg}$ into subpopulations according to their molecular sizes, the purified $\mathrm{Tg}$ was further applied to a Sephacryl S-300 gel filtration column, which had been equilibrated with PBS. Elution of the column with the same buffer separated the purified Tg into three subpopulations according to the retention volume.

\section{FRTL-5 cell culture}

Rat thyroid follicular FRTL-5 cells were cultured in a modified Ham's F12 medium supplemented with $5 \%$ bovine serum and the six-hormone mixture, which contained TSH, insulin, transferrin, somatostatin, GlyHis-Lys acetate, and hydrocortisone $(6 \mathrm{H}$ medium) as described previously [15].

\section{Preparation and primary culture of porcine thyroid epithelial cells}

Preparation of primary porcine thyroid epithelial cells was carried out according to the method of Isozaki et al. [16] with slight modification. Briefly, to 
the diced thyroid tissue was added $50 \mathrm{ml}$ of dispase solution $(10,000 \mathrm{U})$ and the resultant suspension was incubated at $37^{\circ} \mathrm{C}$ with gentle stirring for $1 \mathrm{hr}$. The suspension was filtered through nylon mesh (\#80) and the residual tissue was further chopped up into finer pieces. The same dispase digestion treatment was applied to the chopped up tissue for $2 \mathrm{hrs}$ at $37^{\circ} \mathrm{C}$. The suspension was then filtered again through nylon mesh (\#100) and the collected filtrate containing the dispersed thyroid epithelial cells was washed with Ham's F12 medium several times. The washed cells were then plated onto 96-well tissue culture plates at a density of $2 \times 10^{3}$ cells/well in the $6 \mathrm{H}$ medium and subjected to the cell proliferation assay.

\section{Thyroid cell proliferation assays}

Proliferation of FRTL-5 cells and porcine thyroid epithelial cells were measured by two different methods, the $\left[{ }^{3} \mathrm{H}\right]$-thymidine or the BrdU incorporation assay and the colorimetric assay using the cell counting kit, which utilized water-soluble tetrazolium-1 (WST-1) as a chromogenic substrate. The $\left[{ }^{3} \mathrm{H}\right]$-thymidine incorporation assay was carried out as previously described [15]. Briefly, the cells were plated at a density of $2.5 \times 10^{4}$ cells/well in a 24 -well tissue culture plate and cultured for 3 days in the $6 \mathrm{H}$ medium. The medium was then replaced by the $4 \mathrm{H}$ medium $(6 \mathrm{H}$ medium minus TSH and insulin) and the cells cultured for 2 more days. Then the test samples in $4 \mathrm{H}$ medium were added and the cells cultured for 1 more day. On the seventh day, $\left[{ }^{3} \mathrm{H}\right]$-thymidine $(0.1 \mu \mathrm{Ci} /$ well $)$ was added to each well and the cells further cultured for another day. After washing, the cells were solubilized and the radioactivity of $\left[{ }^{3} \mathrm{H}\right]$-thymidine incorporated into the cellular DNA was measured. The BrdU incorporation assay was performed as follows. The plated cells were cultured for 1 day in the $6 \mathrm{H}$ medium followed by culturing for 2 days in the $4 \mathrm{H}$ medium. The test samples were added and the cells further cultured for 3 days in the $4 \mathrm{H}$ medium. The BrdU labeling solution was then added to each well and the cells incubated for $3 \mathrm{hr}$. DNA synthesis in the treated cells was measured using the BrdU labeling kit according to the manufacturer's instruction. The colorimetric assay was performed as follows. The cells were plated at a density of $1 \times 10^{3}$ cells/well in a 96-well tissue culture plate and cultured for 2 days in the $6 \mathrm{H}$ medium. The medium was then replaced by the $4 \mathrm{H}$ medium and the cells cultured for 4 more days. Then the test samples in $4 \mathrm{H}$ medium were added and the cells further cultured for another 4 days. After washing, WST-1 reagent was added to each well and the amount of cell proliferation was determined by measuring the absorbance at $415 \mathrm{~nm}$.

\section{Removal of $N$-linked oligosaccharides from porcine thyroglobulin}

To $600 \mu \mathrm{g}$ of the purified porcine $\mathrm{Tg}(\mathrm{pTg})$ in PBS, $10 \mathrm{mU}$ of $\mathrm{N}$-glycosidase $\mathrm{F}$ was added and the mixture incubated for $24 \mathrm{hr}$ at $37^{\circ} \mathrm{C}$. The reaction mixture was then applied to a Sephacryl S-300 column to separate the deglycosylated pTg from the enzyme and the liberated carbohydrate. The deglycosylated pTg was lyophilized and dialyzed against PBS before being used in the cell proliferation assay.

\section{Results}

Bovine thyroglobulin dose-dependently stimulated FRTL-5 cell proliferation

To determine whether $\mathrm{Tg}$ has any proliferative effect on thyroid cells, we first cultured FRTL-5 cells with the commercially available purified bovine thyroglobulin (bTg). Addition of increasing concentrations of bTg to the FRTL-5 cell culture medium stimulated the proliferation of the cells in a dose-dependent manner as measured by the $\left[{ }^{3} \mathrm{H}\right]$-thymidine incorporation assay (Figure 1A). At the concentration of $500 \mu \mathrm{g} / \mathrm{ml}$ of bTg, approximately 5- to 10-fold increase in cell growth was observed. Because the Tg molecule contains various types of carbohydrate chains [17], the proliferative effect of $\mathrm{Tg}$ could be exerted by some growth factors bound by electrostatic interaction to the carbohydrate chains of Tg. To exclude this possibility, we added specific monoclonal antibodies against Tg, FGF-1 and FGF-2 in the bTg-containing culture medium to perform the FRTL-5 cell proliferation assay. The results showed that only the addition of antihuman Tg antibody (Figure 1B) but not the addition of either anti-FGF-1 or anti-FGF-2 antibody (Figure 1C) could neutralize the stimulatory effect of bTg on the proliferation of FRTL-5 cells. 

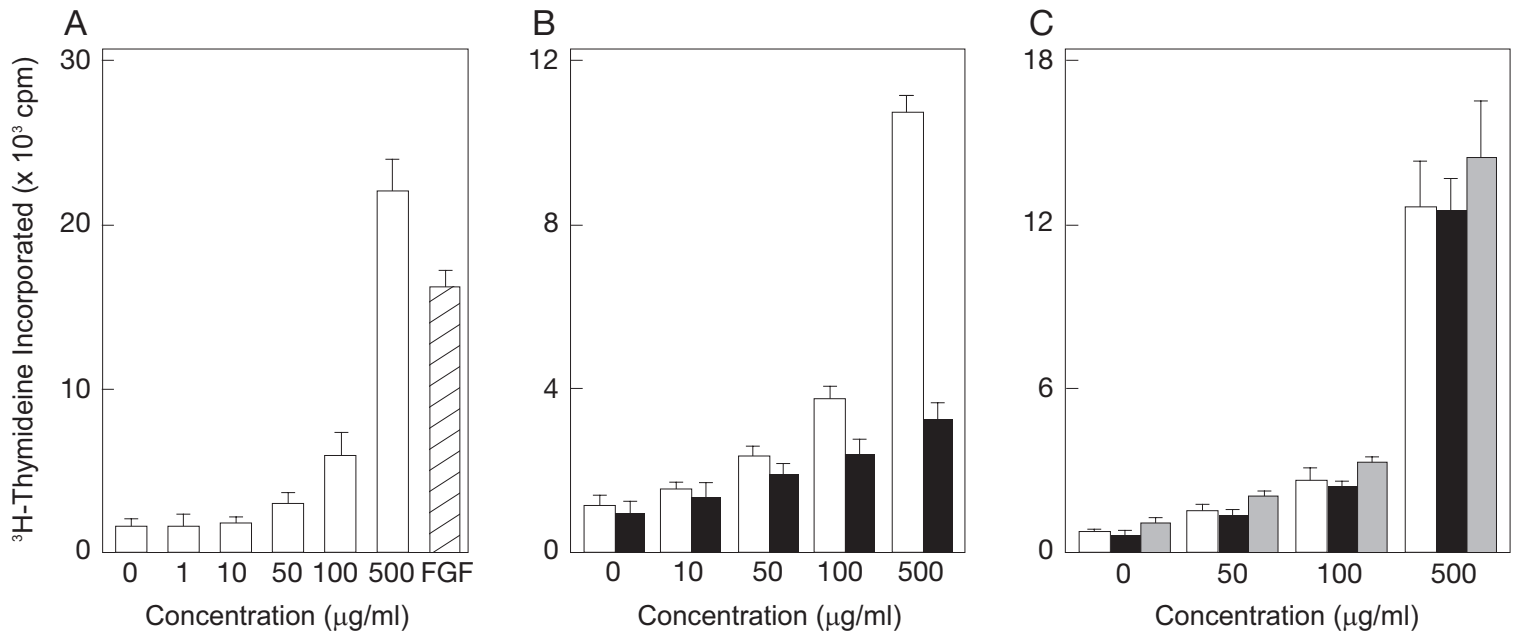

Fig. 1. Proliferative effects of bTg alone and in the presence of anti-human Tg monoclonal antibody or anti-FGF antibodies on FRTL-5 cells.

A) Increasing concentrations of bTg were added to the FRTL-5 cell culture as described in Materials and Methods. Cell proliferative activity was determined by the $\left[{ }^{3} \mathrm{H}\right]$-thymidine incorporation assay. FGF: $10 \mathrm{ng} / \mathrm{ml} \mathrm{FGF-2.} \mathrm{B)} \mathrm{Ten} \mu \mathrm{g} / \mathrm{ml}$ of anti-human $\mathrm{Tg}$ monoclonal antibody (filled bars) or $10 \mu \mathrm{g} / \mathrm{ml}$ of normal mouse IgG (open bars) were added to increasing concentrations of bTg to determine the proliferative activity on FRTL-5 cells. C) Similar to B, $10 \mu \mathrm{g} / \mathrm{ml}$ of anti-FGF-1 antibody (filled bars), $10 \mu \mathrm{g} / \mathrm{ml}$ of anti-FGF-2 antibody (halftone bars), or $10 \mu \mathrm{g} / \mathrm{ml}$ of normal mouse IgG (open bars) were added to increasing concentrations of bTg. The anti-FGF antibodies at the concentration used for this neutralization assay completely inhibited the proliferation of FRTL-5 cells induced by FGF-1 or FGF-2. The values are means \pm SD of triplicate wells from one representative result of three independent experiments.

A

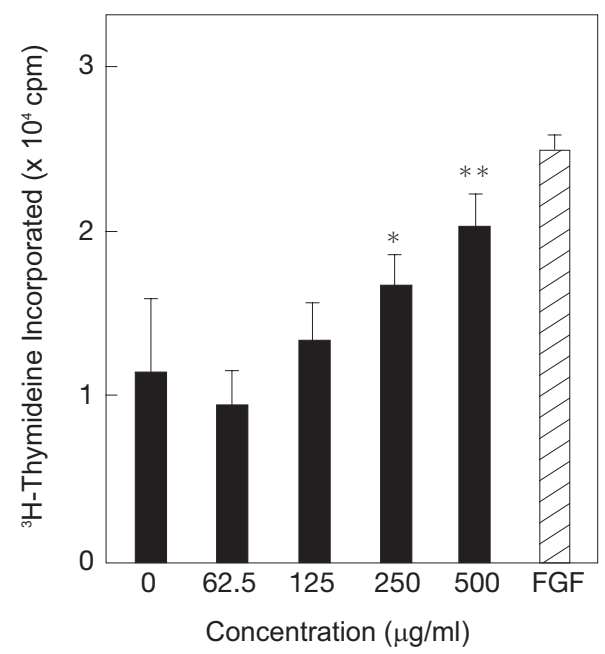

B

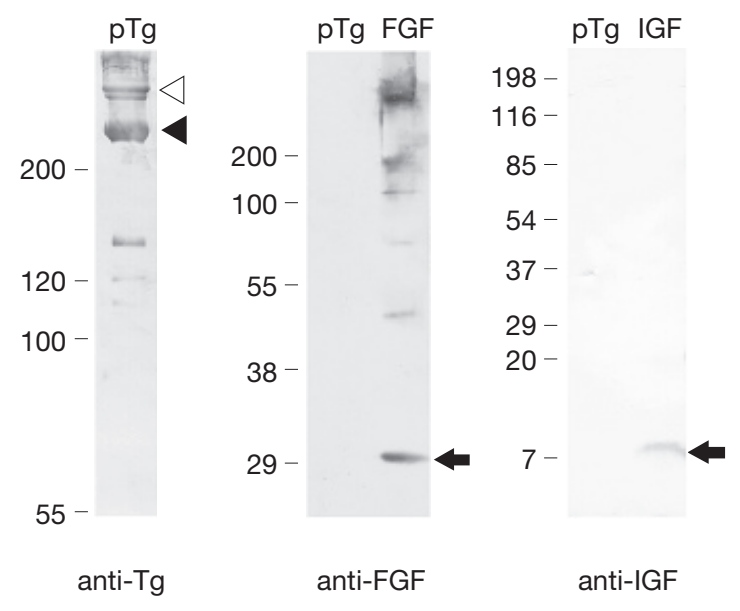

Fig. 2. Proliferative effect exerted by pTg on FRTL-5 cells and no contamination of the purified Tgs with FGF or IGF-I.

A) Increasing concentrations of pTg were added to the FRTL-5 cell culture and the resulting proliferative activities were determined by the $\left[{ }^{3} \mathrm{H}\right]$-thymidine incorporation assay. FGF: $10 \mathrm{ng} / \mathrm{ml} \mathrm{FGF-2}$. The values are means \pm SD of triplicate wells from one representative result of three independent experiments. Unpaired t tests were used to assess significant differences between control and Tg-treated cultures. *: $\mathrm{p}<0.05$; *: $\mathrm{p}<0.01$. B) Purified $\mathrm{pTg}$ was analyzed by Western blotting using anti-human Tg monoclonal antibody (1:2,000 dilution; left panel), anti-FGF-2 antibody (1:1,000 dilution; center panel), or antiIGF-I antibody (1:500 dilution; right panel). The filled arrowhead denotes the monomeric form of Tg and the open arrowhead denotes the dimeric form of Tg. The positive FGF-2 or IGF-I control band on each gel is denoted by the arrows on the right. Molecular weight markers in $\mathrm{kDa}$ are shown on the left. 

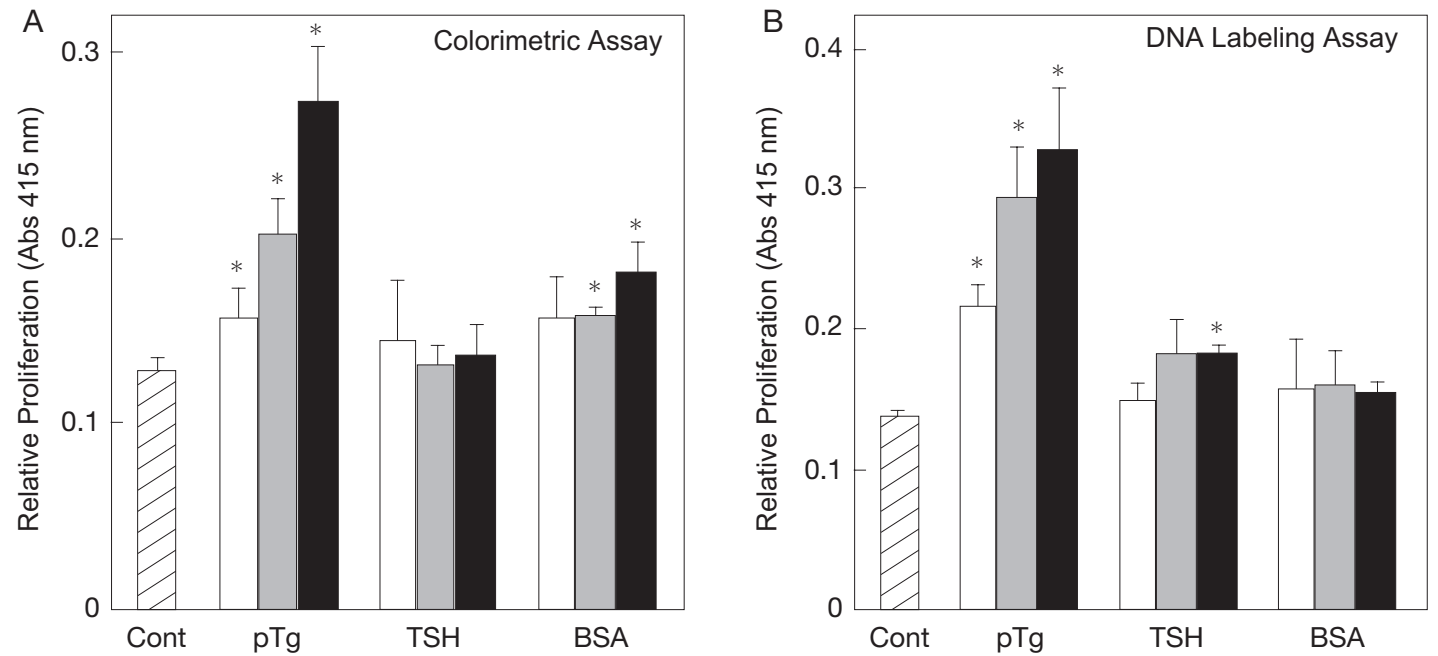

Fig. 3. Prolifetative effects of $\mathrm{pTg}$ on the primary culture of porcine thyroid epithelial cells.

A) Increasing concentrations of pTg $(1.25,2.5,5.0 \mathrm{mg} / \mathrm{ml})$, TSH $(12.5,50,200 \mu \mathrm{U} / \mathrm{ml})$, and BSA $(1.25,2.5,5.0 \mathrm{mg} / \mathrm{ml}) \mathrm{were}$ added to the primary culture and cell proliferation was measured by the colorimetric assay. B) Similar to A, pTg, TSH, and BSA were added to the epithelial cells and cell proliferation was measured by the BrdU labeling assay. Note that open, halftone, and filled bars denote the lowest, middle, and highest concentrations of each sample, respectively. The values are means \pm SD of quadruplicate wells from one representative result of three independent experiments. Unpaired tests were used to assess significant differences between control and Tg-treated cultures. *: $\mathrm{p}<0.05$ vs. control.

\section{Proliferative effect of porcine thyroglobulin on FRTL-5 cells}

Since we have no information on how bTg was purified or its purity, we purified Tg from porcine thyroid tissues and examined the purified materials on the FRTL-5 cell proliferation assay. From the results shown in Figure 2A, pTg was found to stimulate FRTL-5 cell proliferation in a dose-dependent manner like bTg as measured by the $\left[{ }^{3} \mathrm{H}\right]$-thymidine incorporation and an $80 \%$ increase in cell growth was observed at $500 \mu \mathrm{g} / \mathrm{ml}$. Similar cell proliferation assay results were obtained by using the colorimetric assay. These findings showed that both porcine $\mathrm{Tg}$ and bovine $\mathrm{Tg}$ have proliferative effects on FRTL-5 cells. To confirm that our purified Tg did not contain either FGF-like activity or IGF-I-like activity, pTg was analyzed by Western blotting using an anti-FGF-2 antibody or anti-IGF-I antibody. As shown in Figure 2B center panel, no FGF-reactive bands were detected on the lane loaded with pTg, whereas FGF-reactive bands were detected on the lane loaded with FGF-2. Similar results were found using the IGF-I antibody and IGF-I. No IGF-I-reactive bands were detected on the lane of pTg, even when an excess amount of purified pTg (10 $\mu \mathrm{g}$ ) was loaded on the gel (Figure 2B, right panel).
As expected, Western blotting with the anti-human $\mathrm{Tg}$ monoclonal antibody revealed many positive bands on the lanes loaded with pTg (Figure 2B, left panel). The proliferative activity of $\mathrm{pTg}$ could also be neutralized by co-incubation with the anti-human $\mathrm{Tg}$ monoclonal antibody but not with the anti-FGF-2 antibody in the culture medium (data not shown).

\section{Proliferative effects of bovine and porcine thyroglobulins} on the primary culture of porcine thyroid epithelial cells

To eliminate the possibility that the proliferative effect of Tgs on thyroid cell is confined to a specific cell line, we further examined whether bTg or pTg has any effects on the growth of the primary culture of thyroid epithelial cells prepared from porcine thyroid tissues. We measured the proliferative activity of thyroid epithelial cells by the BrdU incorporation assay and the colorimetric assay using the cell counting kit. As shown in Figure 3A, pTg stimulated the proliferation of porcine thyroid epithelial cells in a dose-dependent manner as determined by the colorimetric assay. At the concentration of $5 \mathrm{mg} / \mathrm{ml}$, pTg stimulated the thyroid epithelial cell proliferation by 2.1 -fold. TSH had no effect on the proliferation of thyroid epithelial cells at up to $200 \mu \mathrm{U} / \mathrm{ml}$. Bovine serum albumin (BSA) at 
A

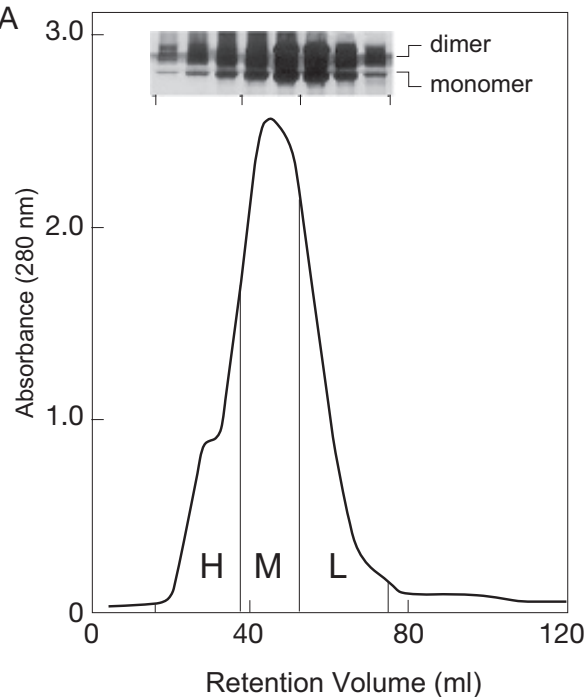

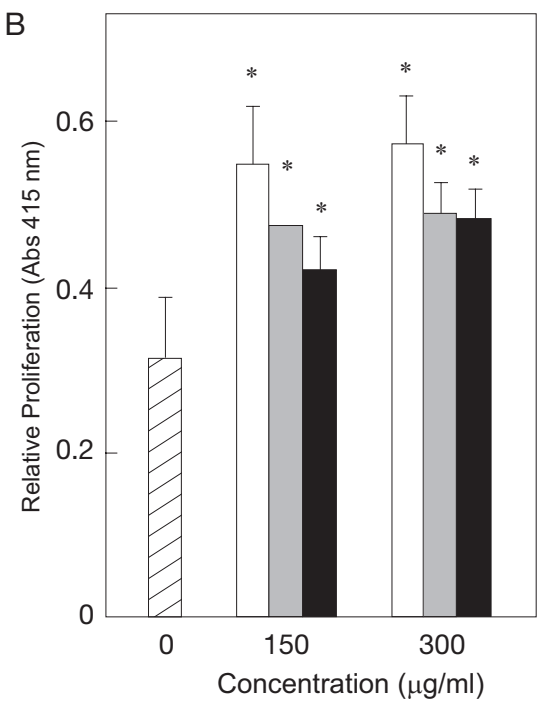

Fig. 4. Separation of pTg into three subpopulations based on molecular size and the proliferative effects exerted by the three subpopulations of pTg on FRTL-5 cells.

A) The purified pTg was separated into three subpopulations, high (H), middle (M) and low (L), by Sephacryl S-300 gel filtration chromatography. The inset shows the profile of each fraction resolved by SDS-PAGE analysis. B) Dose-dependent proliferative effects exerted by each of the three subpopulations, high (open bars), middle (halftone bars) and low (filled bars), of pTg on FRTL-5 cells as determined by the colorimetric assay. The values are means \pm SD of quadruplicate wells from one representative result of three independent experiments. Unpaired t tests were used to assess significant differences between control and Tg-treated cultures. *: $\mathrm{p}<0.05$ vs. without Tg.

the concentrations above $2.5 \mathrm{mg} / \mathrm{ml}$ had a slight stimulatory effect on the proliferation of thyroid epithelial cell, however, its effect was not as potent as pTg. The proliferative effect of $\mathrm{pTg}$ on porcine thyroid epithelial cells was confirmed by the BrdU incorporation assay. As shown in Figure 3B, pTg stimulated the proliferation of porcine thyroid epithelial cells in a dosedependent manner and at the concentration of $5 \mathrm{mg} /$ $\mathrm{ml}$, pTg stimulated the cell proliferation by 2.4 -fold. In this assay, BSA showed no effect on the proliferation while TSH at $200 \mu \mathrm{U} / \mathrm{ml}$ also had little effect on thyroid epithelial cell proliferation. Using both of these assays, we found that bTg also had proliferative effect on porcine thyroid epithelial cells in a dose-dependent manner like pTg (data not shown).

\section{Proliferative effects of Tg subpopulations based on molecular size on FRTL-5 cell proliferation}

Tg molecules are stored in the thyroid follicle as a colloidal solution and they exist in several molecular forms, including insoluble aggregated multimeric forms, and solubule tetrameric, dimeric, and monomeric forms $[18,19]$. We tested whether these various apparent molecular forms of Tg have different proliferative effects on FRTL-5 cells. The different molecular forms of $\mathrm{pTg}$ were isolated by passing the purified pTg through a Sephacryl S-300 gel filtration column, which yielded three subpopulations, high $(\mathrm{H})$, middle (M) and Low (L), according to their apparent molecular sizes (Figure 4A). The profiles of the pTgs from each fraction as determined by SDS-PAGE analysis are shown in Figure 4A inset. When each of the separated high, middle, and low subpopulations of $\mathrm{pTg}$ was tested for its proliferative activity, all three subpopulations at the same concentration showed stimulation of FRTL-5 cell proliferation with similar potency between the subpopulations (Figure 4B).

\section{Involvement of the carbohydrate moiety of thyroglobu-} lin on FRTL-5 cell proliferation

Since the attached carbohydrates on Tg are approximately $10 \%$ of its molecular mass, the carbohydrate moiety could contribute to the stimulatory activity of Tg on FRTL-5 cell proliferation. To address this issue, we remove the carbohydrates on the purified $\mathrm{pTg}$ by treating it with $\mathrm{N}$-glycosidase $\mathrm{F}$, followed by gel 


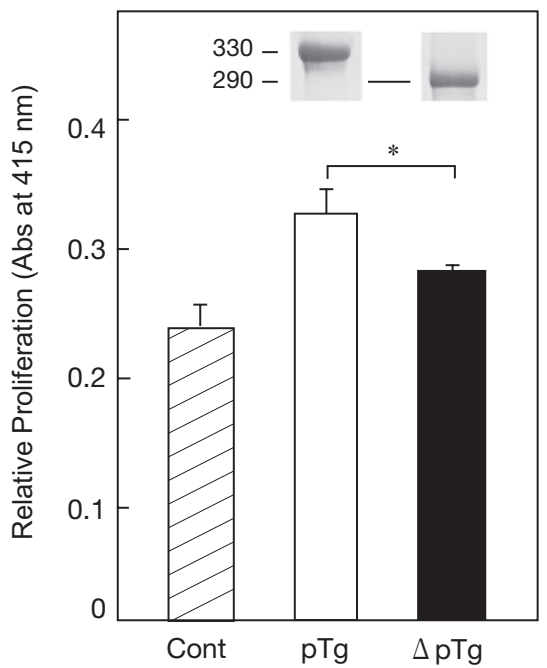

Fig. 5. Involvement of the carbohydrate moiety of pTg on the proliferation of FRTL- 5 cells.

FRTL-5 cells were treated without (Cont: hatched bar), with $100 \mu \mathrm{g} / \mathrm{ml}$ of the purified pTg (pTg: open bar) or with $100 \mu \mathrm{g} / \mathrm{ml}$ of the deglycosylated pTg $(\Delta \mathrm{pTg}$ : filled bar) and cell proliferation was measured by the colorimetric assay. The values are means \pm SD of quadruplicate wells from one representative result of three independent experiments. Unpaired $t$ tests were used to assess significant differences between groups. $*: p<0.05$. The inset shows the molecular masses of the glycosylated and deglycosylated Tgs resolved by SDS-PAGE analysis.

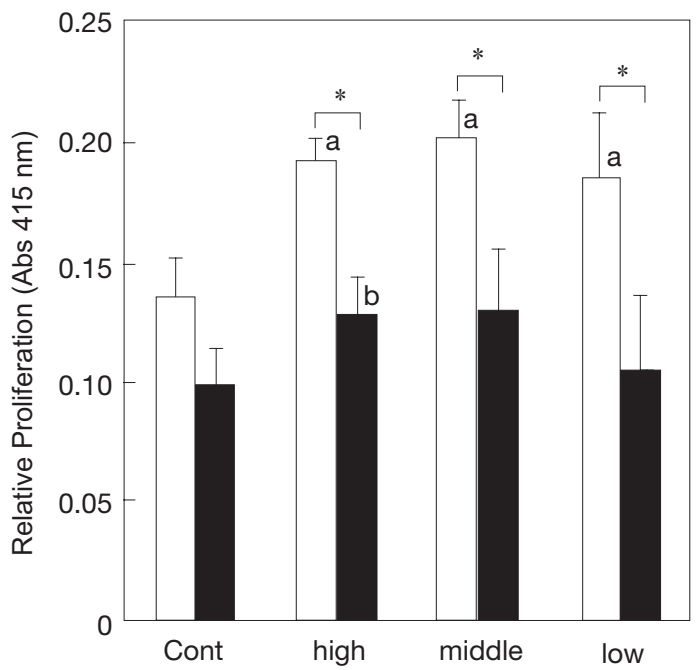

Fig. 6. Inhibition of the stimulatory effect of pTg on FRTL-5 cell proliferation by the PI3K inhibitor wortmannin. Three different molecular size subpopulations of $\mathrm{pTg}$ (high, middle and low) were added at $300 \mu \mathrm{g} / \mathrm{ml}$ to FRTL-5 cells and the cells cultured in the absence (open bars) or in the presence (filled bars) of $100 \mathrm{nM}$ wortmannin. Cell proliferation was determined by the colorimetric assay. Cont: without $\mathrm{Tg}$. The values are means \pm SD of quadruplicate wells from one representative result of three independent experiments. Unpaired t tests were used for the statistical analysis. $*$ : $p<0.05$ with vs. without wortmannin; a: $p<0.05$ vs. control (without $\mathrm{Tg}$, without wortmannin); $\mathrm{b}: \mathrm{p}<0.05$ vs. control (without $\mathrm{Tg}$, with wortmannin).

also been well examined, although some discrepancies still exist. To elucidate whether the signaling pathway employed by Tg on FRTL-5 cell proliferation is the same as that used by TSH and/or insulin, wortmannin, a phosphatidylinositol 3-kinase (PI3K) inhibitor, was added to the culture medium of FRTL- 5 cells in the presence of pTg. As shown in Figure 6, in the absence of wortmannin each subpopulation of $\mathrm{pTg}$ stimulated the proliferation of FRTL-5 cells but in the presence of wortmannin a significant decrease of the proliferative activity was noted in the each of these three pTg subpopulations (open bars vs. filled bars). Wortmannin, however, did not decrease the proliferation of the control culture significantly. The proliferative activities on FRTL-5 cells exerted by the middle and the low molecular size subpopulations of pTg were decreased down to the basal level by wortmannin, while only the high molecular size subpopulation of $\mathrm{pTg}$ showed a slight resistance against the inhibition by wortman- 
nin. Thus, the signaling pathway employed by $\mathrm{Tg}$ on FRTL-5 cell proliferation could also be mediated through PI3K like TSH and /or insulin/IGF-I.

\section{Discussion}

The purpose of this study was to determine whether $\mathrm{Tg}$ has additional functions besides serving as a precursor for the thyroid hormones and acting as a transcriptional regulator on thyroid specific genes. Since the plasma concentration of Tg is very low $(5-30 \mathrm{ng} /$ $\mathrm{ml}$ ) under normal physiological conditions, we examined the role of $\mathrm{Tg}$ as a growth regulator directly on the thyroid epithelial cells. Two different methods were employed to measure the cell proliferative activity, one by measuring the total DNA in the cultured cells based on $\left[{ }^{3} \mathrm{H}\right]$-thymidine or BrdU incorporation and the other by measuring the metabolic activity of the cultured cells using WST-1 with a colorimetric assay. We also measured the cell proliferative activity by directly counting the total number of cells, and found that the activities of cell proliferation have a better correlation when they were measured by direct cell counting versus the colorimetric assay than when they were measured by direct cell counting versus the DNA labeling assay (data not shown). Using these two assays, bovine and porcine Tgs were found to stimulate the proliferation of FRTL-5 cells in a dosedependent manner. In addition, both Tgs stimulated the proliferation of the porcine epithelial cells in primary culture. By contrast, TSH, the primary regulator of thyroid gland, had no effect on thyroid cell proliferation as measured by the colorimetric assay and only a slight stimulatory effect on DNA synthesis in thyroid cells, and these results are consistent with the previously published investigations [reviewed in 9]. In addition, serum albumin, which is also present in the thyroid follicle, slightly affected the proliferation of porcine thyroid epithelial cells in the colorimetric assay at the higher concentrations but not in the DNA labeling assay. Because the colorimetric assay is known to be affected by cell volume independent of cell proliferation, the measured proliferation by BSA in this assay might reflect cell volume increase rather than cell proliferation. To determine whether the stimulatory effects of $\mathrm{Tg}$ on rat and porcine thyroid epithelial cells were specific, we performed the same proliferative assay on TSU-prl cells, a prostate epithelial car- cinoma-derived cell line, and bovine aortic endothelial cells. Unlike the FRTL-5 cells or porcine thyroid epithelial cells, pTg did not stimulate the proliferation of TSU-pr1 cells and endothelial cells (data not shown). These data suggest that the proliferative effect of $\mathrm{Tg}$ on thyroid cells is specific.

The effective dosages of bTg or pTg for the proliferation of thyroid cells observed in this report are $0.5 \mathrm{mg} / \mathrm{ml}$ on FRTL- 5 cells and $5 \mathrm{mg} / \mathrm{ml}$ on porcine thyroid epithelial cells. Since the concentration of $\mathrm{Tg}$ stored in the follicles formed by the thyroid epithelial cells range between 100 to $400 \mathrm{mg} / \mathrm{ml}[2,3]$, the highly effective dosage of $5 \mathrm{mg} / \mathrm{ml}$ of Tg is somewhat lower than the physiological concentration of Tg stored in the thyroid. However, Suzuki et al. [5, 6] has demonstrated considerable heterogeneity regarding the concentration of $\mathrm{Tg}$ stored in each follicle, some containing much more Tg than the others. Due to the difficulty in preparing soluble Tg at higher concentrations, it is difficult to determine whether the stimulatory effects of Tgs on thyroid cell proliferation could be further increased in higher Tg concentrations. On the other hand, it could be argued that the proliferative effect of Tg is exerted only when the concentration of stored Tg decreases down to a critical level or that the follicular structure is somewhat deformed. It is well known that the bioactivities of growth factors and angiogenic factors on adult normal thyroids are strictly regulated, and angiogenesis and cell growth do not occur in the mature organ. On the other hand, it has been proposed that angiogenic factors and growth factors may be activated in some pathological situations such as inflammation, tissue injury and neoplastic growth. Neoplastic growth depends on the balance of growth factors and inhibitors as well as interactions with extracellular matrix and vascular control [20,21]. $\mathrm{Tg}$ could participate in the proliferation of thyroid cells under such circumstances.

In physiological conditions, Berndorfer et al. [18] reported that $\mathrm{Tg}$ stored in the thyroid follicles existed in two distinct forms, one of which was soluble and contained monomeric, dimeric, and tetrameric Tgs, whereas the other was insoluble with $\mathrm{Tg}$ present in multimeric states, which formed large colloidal globules. Therefore, we examined whether the different molecular species of soluble Tg could have different effects on the proliferation of FRTL- 5 cells. Three subpopulations of porcine $\mathrm{Tg}$, high, middle and low, based on their molecular sizes, were isolated and ex- 
amined on the cell proliferation assay. All three subpopulations of pTg showed stimulation of FRTL-5 cell proliferation, and the stimulatory effects exerted by these three subpopulations showed no significant difference. Because of the impossibility of adding the insoluble form of $\mathrm{Tg}$ to the culture dish where the proliferation assay is being carried out, we cannot ascertain whether the insoluble multimeric form of $\mathrm{Tg}$ has any effect on the proliferation of thyroid cells.

Since FGF-2 is present in the thyroid bound to heparin and FGF-2 is one of the important local modulators of thyroid function and cell growth [15], we examined whether the stimulatory effect of Tgs on FRTL-5 cells and porcine thyroid cells could be due to FGF-2 contamination. We found that this was not the case for the following reasons. First, the Tgs were purified on a gel filtration column under high salt conditions to dissociate any bound FGF to Tg. Second, the stimulatory effect of $\mathrm{Tg}$ could only be neutralized by an anti-human $\mathrm{Tg}$ monoclonal antibody but not by two anti-FGF monoclonal antibodies. Third, no FGF could be detected by Western blotting in the purified Tgs. IGF-I is also known to stimulate the growth of thyroid cells in culture and stimulate DNA synthesis induced by TSH [11]. However, we could not detect the presence of any IGF-I by western blotting in the $\mathrm{Tg}$ preparation used in the proliferation assay. Therefore, it is unlikely that the stimulatory effect of $\mathrm{Tg}$ on cell growth is due to IGF-I contamination. These findings indicate that $\mathrm{Tg}$ itself has intrinsic stimulatory activity on FRTL-5 and porcine thyroid cell proliferation.

The importance of the carbohydrate moiety in the $\mathrm{Tg}$ molecule has been pointed out by several investigators. Ikekita et al. [22] reported that the N-linked oligosaccharide in $\mathrm{Tg}$ was required for the iodine organification and Mziaut et al. [23] showed that both the carbohydrate and the protein determinants in $\mathrm{Tg}$ were involved in Tg recognition by FRTL-5 cells. Miquelis et al. [24] reported that the carbohydrate moiety affected the recycling of Tg via the Golgi apparatus. Furthermore, Park et al. [25] demonstrated that a defective carbohydrate moiety could cause the failure of Tg to dimerize and be secreted from the thyroid cells and Desruisseau et al. [26] showed that the carbohydrate content of $\mathrm{Tg}$ in the cultured porcine thyroid cells could be increased by TSH. These observations indicate that the carbohydrate moiety of $\mathrm{Tg}$ is very important for the function of $\mathrm{Tg}$, especially in biosynthesis and release of the thyroid hormones. Our results obtained in this study also substantiated the significance of the carbohydrate moiety in Tg because we showed that deletion of the N-linked oligosaccharide in $\mathrm{pTg}$ diminished the stimulatory effects of $\mathrm{pTg}$ on FRTL-5 cell proliferation. We previously reported that $\mathrm{Tg}$ in human papillary thyroid carcinomas had an altered state of sulfation in the chondroitin sulfate chain compared to Tg from normal tissues [27]. It is not clear whether the change in sulfation status represents the cause or the result of the formation of carcinomas but it is tempting to speculate that the presence of an altered chondroitin sulfate chain could affect the stimulatory effect of Tg on FRTL-5 cell proliferation. However, investigation of the effects of Tgs obtained from normal human thyroid tissue and thyroid carcinomas on the proliferation of thyroid cells will need to be conducted to address this issue.

Growth of thyroid cells is regulated by TSH and insulin and the signaling pathways employed by TSH have been extensively examined [9]. Therefore, we also attempted to explore the signaling pathway employed by Tg in stimulating FRTL-5 cell proliferation. Our results showed that Tg signaling in FRTL-5 cells was mediated through PI3K because the proliferative effect of Tg was blocked by the PI3K antagonist wortmannin. PI3K participates in various cellular processings, including cell proliferation and intracellular trafficking. In thyroid cells TSH activates this pathway by elevating the level of cAMP in the cells through the activation of adenylyl cyclase, a downstream effecter of the TSH receptor [28, 29]. Marino et al. [30] also demonstrated that PI3K exerted an inhibitory effect on megalin-mediated $\mathrm{Tg}$ transcytosis across the cultured FRTL-5 cells. It has been postulated that Tg transcytosis plays an important role in the regulation of thyroid function [31]. Most of the Tgs enter thyroid cells by nonspecific micropinocytosis, whereas some $\mathrm{Tg}$ molecules are recycled back into the follicular lumen via the asialoglycoprotein receptor [32] or transported by transcytosis via megalin [31]. Since the effective dosage of Tgs observed in our proliferation assay was much lower than the concentration of $\mathrm{Tg}$ stored in the follicles, the Tg molecules are unlikely to be internalized via micropinocytosis. The stimulatory signal of Tg might be transmitted in the cells either by binding to a hitherto unknown receptor or by receptormediated endocytosis via the asialoglycoprotein receptor or megalin. Our results demonstrating that the stimulation of thyroid cell growth by $\mathrm{Tg}$ is mediated 
through PI3K imply the involvement of megalin-mediated transcytosis in the signaling of the Tg-induced stimulation of thyroid cell proliferation. Although further research is needed to determine which receptor facilitates the signaling of $\mathrm{Tg}$ and how the stimulatory signal of Tg is transmitted in the cells in order to elucidate the mechanism of Tg-stimulated FRTL-5 cell proliferation, we have demonstrated for the first time that thyroglobulin possesses proliferative effect on thyroid cells.

\section{Acknowledgments}

We are deeply grateful to Dr. Nicholas Ling, Neurocrine Biosciences, for critical reading of the manuscript and helpful advice and discussions. We also thank Mr. Hiroki Tsutsumi and Ms. Masayo Ashizawa for their technical assistance.

\section{References}

1. van de Graaf SAR, Ris-Stalpers C, Pauws E, Mendive FM, Targovnik HM, de Vijlder JJM (2001) Up to date with human thyroglobulin. J Endocrinol 170: 307-321.

2. Smeds S (1972) A microgel electrophoretic analysis of the colloid proteins in single rat thyroid follicles. II. The protein concentration of the colloid in single rat thyroid follicles. Endocrinology 91: 1300-1306.

3. Hayden LJ, Shagrin JM, Young JA (1970) Micropuncture investigation of the anion content of colloid from single rat thyroid follicles. Pfueger Arch Gesamte Physiol Menschen Tiere 321: 173-186.

4. Suzuki K, Lavaroni S, Mori A, Ohta M, Saito J, Pietrarelli M, Singer DS, Kimura S, Katoh R, Kawaoi A, Kohn LD (1998) Autoregulation of thyroid-specific gene transcription by thyroglobulin. Proc Natl Acad Sci USA 95: 8251-8256.

5. Suzuki K, Mori A, Lavaroni S, Miyagi E, Ulianich L, Katoh R, Kawaoi A, Kohn LD (1999) In vivo expression of thyroid transcription factor-1 RNA and its relation to thyroid function and follicular heterogeneity. Thyroid 9: 319-331.

6. Suzuki K, Mori A, Saito J, Moriyama E, Ullianich L, Kohn LD (1999) Follicular thyroglobulin suppresses iodide uptake by suppressing expression of the sodium/ iodide symporter gene. Endocrinology 140: 5422-5430.

7. Huang SS, Cerullo MA, Huang FW, Huang JS (1998) Activated thyroglobulin possesses a transforming growth factor-beta activity. $J$ Biol Chem 173: 2603626041.

8. Sellitti DF, Suzuki K, Doi SQ, LaGranha C, Machado M, Matos T, Kohn LD (2001) Thyroglobulin increases cell proliferation and suppresses Pax- 8 in mesangial cells. Biochem Biophys Res Commun 285: 795-799.

9. Kimura T, Van Keymeulen A, Golstein J, Fusco A, Dumont JE, Roger PP (2001) Regulation of thyroid cell proliferation by TSH and other factors: a critical evaluation of in vitro models. Endocrinol Rev 22: 631-656.

10. Brandi ML, Rotella CM, Mavilia C, Franceschelli F, Tanini A, Toccafondi R (1987) Insulin stimulates cell growth of a new strain of differentiated rat thyroid cells. Mol Cell Endocrinol 54: 91-103.

11. Zakarija M, McKenzie JM (1989) Variations in the culture medium for FRTL5 cells: effects on growth and iodide uptake. Endocrinology 125: 1253-1259.

12. Black EG, Logan A, Davis JR, Sheppard MC (1990) Basic fibroblast growth factor affects DNA synthesis and cell function and activates multiple signaling pathways in rat thyroid FRTL-5 and pituitary GH3 cells. $J$ Endocrinol 127: 39-46.

13. Asmis LM, Gerber H, Kaempf J, Studer H (1995) Epidermal growth factor stimulates cell proliferation and inhibits iodide uptake of FRTL-5 cells in vitro. $J$ Endocrinol 145: 513-520.

14. Marino M, Friedlander JA, McCluskey RT, Andrews D (1999) Identification of a heparin-binding region of rat thyroglobulin involved in megalin binding. $J$ Biol Chem 274: 30377-30386.

15. Emoto N, Isozaki O, Arai M, Murakami H, Shizume K, Baird A, Tsushima T, Demura H (1991) Identification and characterization of basic fibroblast growth factor in porcine thyroids. Endocrinology 128: 58-64.

16. Isozaki O, Tsushima T, Shizume K, Saji M, Ohba Y, Emoto N, Sato K, Sato Y, Kusakabe K (1985) Thyroidstimulating antibody bioassay using porcine thyroid cells cultured in follicles. J Clin Endocrinol Metab 61: 1105-1111.

17. Yang SX, Pollock HG, Rawitch AB (1996) Glycosylation in human thyroglobulin: Location of the $\mathrm{N}$-linked oligosaccharide units and comparison with bovine thyroglobulin. Arch Biochem Biophys 327: 61-70.

18. Berndorfer U, Wilms H, Herzog V (1996) Multimerization of thyroglobulin (TG) during extracellular storage: Isolation of highly cross-linked TG from human thyroids. J Clin Endocrinol Metab 81: 1918-1926.

19. Delom F, Mallet B, Carayon P, Lejeune PJ (2001) Role of extracellular molecular chaperones in the folding of oxidized proteins. Refolding of colloidal thyroglobu- 
lin by protein disulfide isomerase and immunoglobulin heavy chain-binding protein. J Biol Chem 276: $21337-$ 21342.

20. Emoto N, Onose H, Sugihara H, Minami S, Shimizu K, Wakabayashi I (1998) Fibroblast growth factor-2 free from extracellular matrix is increased in papillary thyroid carcinomas and Graves' thyroids. Thyroid 8: 491497.

21. Turner HE, Harris AL, Melmed S, Wass JA (2003) Angiogenesis in endocrine tumors. Endocrinol Rev 24: 600-632.

22. Ikekita M, Yajima H, Murata T, Takatera K, Watanabe T, Sonoyama M, Tezuka Y, Ishii T, Tarutani O (1997) Carbohydrate analysis of porcine thyroglobulin isoforms with different iodine contents. Biochim Biophys Acta 1336: 557-565.

23. Mziaut H, Bastiani P, Balivet T, Papandreou MJ, Fert V, Erregragui K, Blanck O, Miquelis R (1996) Carbohydrate and protein determinants are involved in thyroglobulin recognition by FRTL-5 cells. Endocrinology 137: 1370-1377.

24. Miquelis R, Courageot J, Jacq A, Blanck O, Perrin C, Bastiani P (1993) Intracellular routing of GlcNAcbearing molecules in thyrocytes: Selective recycling through the Golgi apparatus. J Cell Biol 123: 16951706.

25. Park YN, Arvan P (2004) The acetylcholinesterase homology region is essential for normal conformational maturation and secretion of thyroglobulin. $\mathrm{J} \mathrm{Biol} \mathrm{Chem}$ 279: 17085-17089.

26. Desruisseau S, Franc JL, Gruffat D, Chabaud O (1994) Glycosylation of thyroglobulin secreted by porcine cells cultured in chamber system: Thyrotropin controls the number of oligosaccharides and their anionic resi- dues. Endocrinology 134: 1676-1684.

27. Emoto N, Kunii YK, Ashizawa M, Oikawa S, Shimizu K, Shimonaka M, Toyoda A, Toyoda H (2007) Reduced sulfation of chondroitin sulfate in thyroglobulin derived from human papillary thyroid carcinomas. Cancer Sci 98: 1577-1581.

28. Ciullo I, Diez-Roux G, Di Domenico M, Migliaccio A, Avvedimento EV. (2001) cAMP signaling selectively influences Ras effectors pathways. Oncogene 20: 11861192.

29. Suh JM, Song JH, Kim DW, Kim H, Chung HK, Hwang JH, Kim JM, Hwang ES, Chung J, Han JH, Cho BY, Ro HK, Shong M (2003) Regulation of the phosphatidylinositol 3-kinase, Akt/protein kinase B, FRAP/mammalian target of rapamycin, and ribosomal S6 kinase-1 signaling pathways by thyroid-stimulating hormone (TSH) and stimulating type TSH receptor antibodies in the thyroid gland. J Biol Chem 278: 2196021971.

30. Marino M, Chiovato L, Lisi S, Pinchera A, McCluskey RT (2001) Phosphoinositide 3-kinase inhibits megalinmediated transcytosis of thyroglobulin across thyroid epithelial cells at a post-sorting level. Eur J Endocrinol 145: 477-483.

31. Marino M, Zheng G, McCluskey RT (1999) Megalin (gp330) is an endocytic receptor for thyroglobulin on cultured fisher rat thyroid cells. J Biol Chem 274: 12898-12904.

32. Montuori N, Pacifico F, Mellone S, Liguoro D, Di Jeso B, Formisano S, Gentile F, Consiglio E (2000) The rat asialoglycoprotein receptor binds the amino-terminal domain of thyroglobulin. Biochem Biophys Res Commun 268: 42-46. 